\title{
Modelowanie własności mechanicznych lekkich struktur wielowarstwowych
}

\begin{abstract}
Ważnym wymaganiem stawianym nowoczesnym środkom transportu, $w$ tym także kolejowym, jest zwiększanie możliwości przewozowych poprzez między innymi obniżanie masy własnej pojazdów. Jednym ze sposobów jest stosowanie w konstrukcjach nośnych pojazdów, lekkich a jednocześnie wysokowytrzymałych struktur na przyktad wielowarstwowych. Podstawe ich budowy stanowiq gładkie warstwy zewnętrzne przedzielone rdzeniem o różnorodnej budowie. W pracy opisano wybrane przykłady takich rozwiazań, przy czym szczególna uwage zwrócono na aluminiowe konstrukcje trójwarstwowe. Ocena możliwości zastosowania takich konstrukcji musi być poprzedzona określeniem podstawowych wtasności mechanicznych. Niezbędne analizy przeprowadzono metoda elementów skończonych. Wyniki analiz w postaci zależności wartości ugięcia od obciażenia zaprezentowano $w$ sposób graficzny. Weryfikacje rezultatów obliczeń MES przeprowadzono porównujac z wynikami badań doświadczalnych. Praca powstata w ramach realizacji projektu rozwojowego Nr 10004706 pt.: „Konstrukcja pojazdu szynowego z zastosowaniem najnowszych lekkich materiałów o wysokich parametrach wytrzymałościowych i o minimalnym oddzialywaniu na środowisko naturalne".
\end{abstract}

\section{Wprowadzenie}

Jednym $\mathrm{z}$ podstawowych celów stawianych współczesnemu transportowi jest między innymi zwiększanie jego możliwości przewozowych. Oprócz zmian organizacyjnych, skutecznym sposobem realizacji powyższego zadania jest stosowanie środków transportu o coraz lżejszej konstrukcji ustroju nośnego. Jedną z możliwości jest wykorzystanie do ich budowy lekkich, a jednocześnie wysokowytrzymałych elementów powierzchniowych o budowie wielowarstwowej. Najczęściej składają się one z blach o stosunkowo wysokiej wytrzymałości, zwanych okładzinami przedzielonych rdzeniem o różnorodnej strukturze. Rdzeń może być wykonane ze spienionego tworzywa (sztucznego jak również z piany metalu), struktury ,plastra miodu” lub pofałdowanej blachy. Najczęściej stosowane są aluminiowe struktury trójwarstwowe. Podstawy teorii struktur wielowarstwowych opisano w [1] i [2].

Konstrukcje wielowarstwowe $\mathrm{w}$ porównaniu do konwencjonalnych jednorodnych blach posiadają następujące zalety:

- mniejsza masa,

- większa sztywność, dzięki czemu istnieje możliwość eliminacji dodatkowych wzmocnień i usztywnień. Powoduje to $\mathrm{z}$ jednej strony zwiększenie przestrzeni użytkowej a z drugiej ułatwienie $\mathrm{w}$ zabudowie wyłożeń wewnętrznych,
- mniejsze koszty wytworzenia i wyposażenia,

- dobra izolacja termiczna i ognioodporność (dzięki przestrzeniom wewnątrz wypełnienia),

- dobre thumienie drgań oraz hałasu.

$\mathrm{W}$ ramach prac związanych $\mathrm{z}$ realizacją zadań projektu rozwojowego podjęto próby sprawdzenia przydatności do zastosowania, w budowie konstrukcji nośnej pojazdu szynowego, aluminiowych elementów powierzchniowych o strukturze trójwarstwowej, głównie na przykładzie wagonu osobowego.

W pierwszym etapie konieczne było opracowanie modeli obliczeniowych MES (Metoda Elementów Skończonych) struktur trójwarstwowych z różnym wypełnieniem. Przeprowadzono szereg analiz w celu wyznaczenia podstawowych własności mechanicznych. Weryfikację przygotowanych modeli przeprowadzono porównując wyniki obliczeń $z$ rezultatami badań doświadczalnych rzeczywistych próbek wykonanych na stanowisku badawczym.

W niniejszym artykule omówiono opracowane modele obliczeniowe $\mathrm{i}$ wyniki analiz oraz oceniono ich przydatność do dalszych symulacji numerycznych konstrukcji nośnych wagonu osobowego. 


\section{Modele struktur trójwarstwowych}

$\mathrm{Na}$ podstawie wstępnego rozpoznania oraz studium literaturowego [3] główną uwagę skupiono na modelowaniu struktur trójwarstwowych składających się $\mathrm{z}$ dwóch płaskich blach przedzielonych rdzeniem $\mathrm{w}$ postaci:

- metalowej piany,

- struktury ulowej (,plastra miodu” - „honeycomb"),

- blachy falistej.

Wszystkie elementy badanych struktur są wykonane $\mathrm{z}$ aluminium, przy czym okładziny $\mathrm{z}$ rdzeniem połączone są za pomocą klejenia.

Ocenę własności mechanicznych przeprowadzono głównie na podstawie rezultatów zginania belek. Rozpatrzono zginanie czteropunktowe. Schemat obciążeń belki oraz rozmieszczenie punktów pomiarowych przedstawiono na Rys. 2.1.

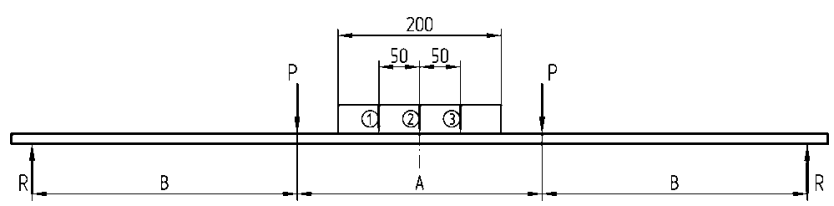

Rys. 2.1.Schemat obciążenia modelu belki trójwarstwowej dla czteropunktowego zginania

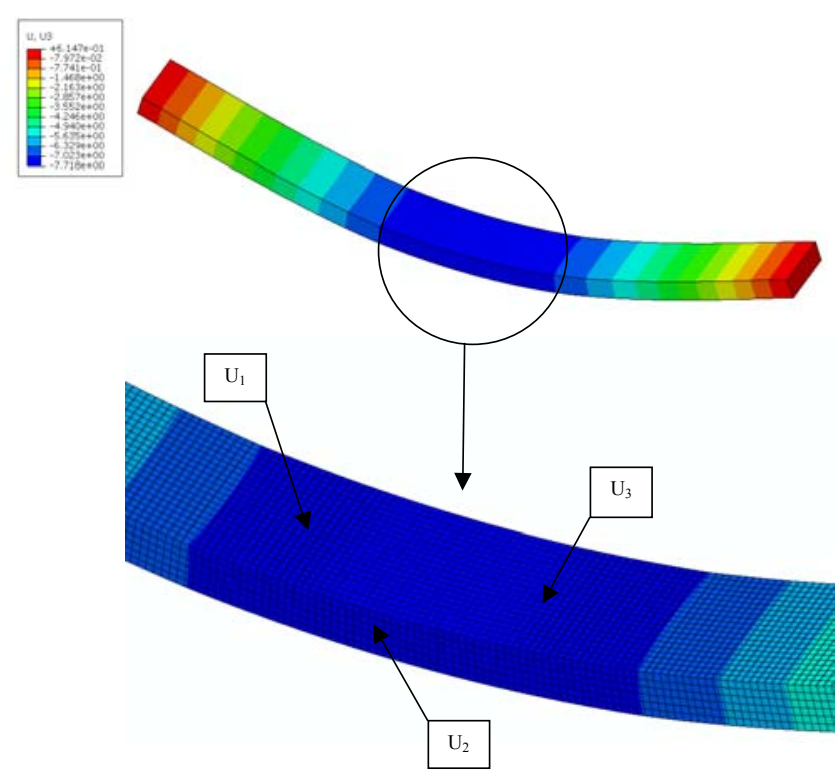

Rys. 2.2.Rozkład przemieszczeń pionowych dla czteropunktowego zginania belki

Szerokości belek w obu przypadkach obciążenia wynoszą $100 \mathrm{~mm}$. Szczegóły geometrii przekrojów poprzecznych przyjęto tak, aby odpowiadały rzeczywistym obiektom poddanym badaniom stanowiskowym.

Niezbędne obliczenia wykonano metodą elementów skończonych (MES). Okładziny belek oraz rdze- nie $\mathrm{z}$ blachy zamodelowano za pomocą elementów powierzchniowych, a rdzeń $\mathrm{z}$ piany aluminiowej elementami bryłowymi. Połączenie okładzin i rdzenia zrealizowano za pomocą połączenia kontaktowego typu ,interaction tie".

Charakterystyczny rozkład przemieszczeń pionowych dla zginania czteropunktowego przykładowo przedstawiono na rys. 2.2.

$\mathrm{Na}$ podstawie wyników sporząadzono wykresy zależności ugięcia belek od przyłożonego obciążenia.

\section{Belka trójwarstwowa z rdzeniem z metalowej piany}

Widok ogólny rozpatrywanej belki oraz szczegóły przekroju poprzecznego przedstawiono na rys. 2.3. Płaskie blachy okładzin maja grubość $1 \mathrm{~mm}$, a całkowita wysokość próbki wynosi $30 \mathrm{~mm}$.

Do analizy przyjęto model obejmujący połówkę wzdłużną belki o długości $1100 \mathrm{~mm}(\mathrm{~A}=300 \mathrm{~mm}$; $\mathrm{B}=370 \mathrm{~mm}$ według rys.2.1). Belkę obciażono tak, aby wywołać w niej zginanie czteropunktowe momentem gnącym o wartości $200 \mathrm{Nm}$. Maksymalna wartość przemieszczenia pionowego pojawia się $\mathrm{w}$ środku belki i wynosi $7.69 \mathrm{~mm}$.

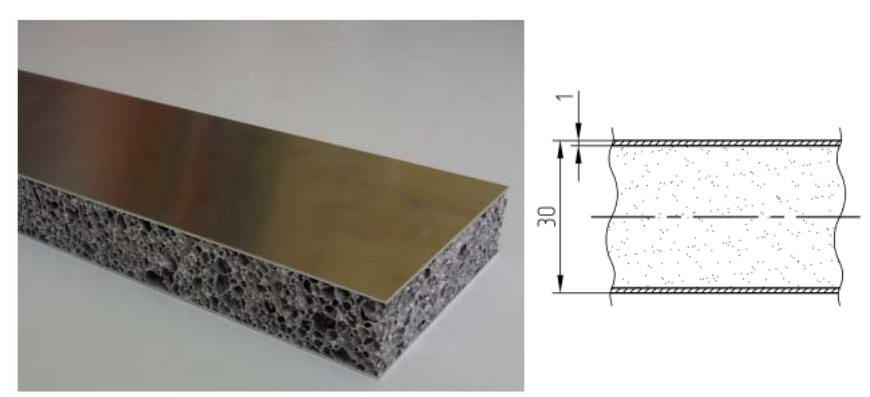

Rys. 2.3. Aluminiowa struktura $\mathrm{z}$ rdzeniem z metalowej piany

\section{Belka trójwarstwowa z rdzeniem o strukturze ulowej (,plastra miodu")}

Widok ogólny struktury trójwarstwowej z rdzeniem o budowie ,plastra miodu”, szczegóły przekroju poprzecznego oraz model obliczeniowy przedstawiono na rys. 2.4. Płaskie okładziny wykonano $\mathrm{z}$ blach o grubości $1 \mathrm{~mm}$, a strukturę ulową z blachy o grubości $0.15 \mathrm{~mm}$. Całkowita wysokość próbki wynosi $30 \mathrm{~mm}$.

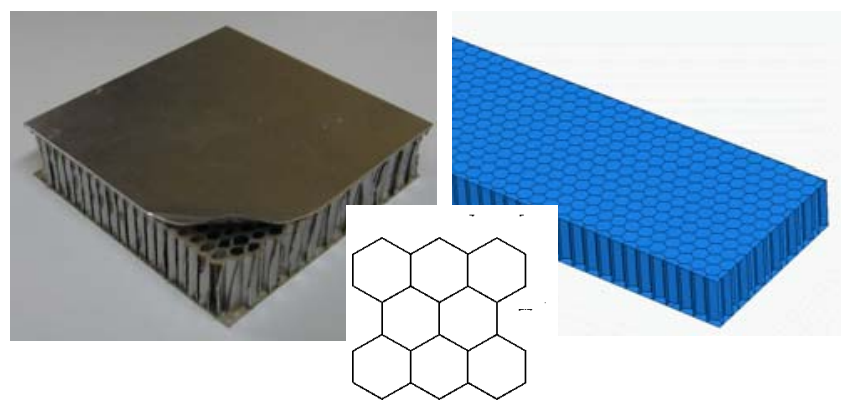

Rys. 2.4. Aluminiowa struktura $\mathrm{z}$ rdzeniem o budowie ,plastra miodu" 
Do analizy przyjęto model obejmujący połówkę wzdłużną belki o długości $1100 \mathrm{~mm}(\mathrm{~A}=300 \mathrm{~mm}$; $\mathrm{B}=370 \mathrm{~mm}$ według rys.2.1). Belkę obciążono tak, aby wywołać w niej zginanie czteropunktowe momentem gnącym o wartości $300 \mathrm{Nm}$. Maksymalna wartość przemieszczenia pionowego pojawia się $\mathrm{W}$ środku belki i wynosi $11.02 \mathrm{~mm}$.

\section{Belka trójwarstwowa z rdzeniem z blachy falistej}

Widok ogólny przykładowej struktury trójwarstwowej z rdzeniem z blachy falistej oraz szczegóły przekroju poprzecznego przedstawiono na rys. 2.5. Płaskie okładziny wykonano $\mathrm{z}$ blach o grubości 1 $\mathrm{mm}$, a rdzeń z blachy falistej o grubości $0.3 \mathrm{~mm}$. Całkowita wysokość próbki wynosi $11.5 \mathrm{~mm}$. Do analizy przyjęto model belki o długości $780 \mathrm{~mm}$ $(\mathrm{A}=\mathrm{B}=250 \mathrm{~mm}$ według rys.2.1).
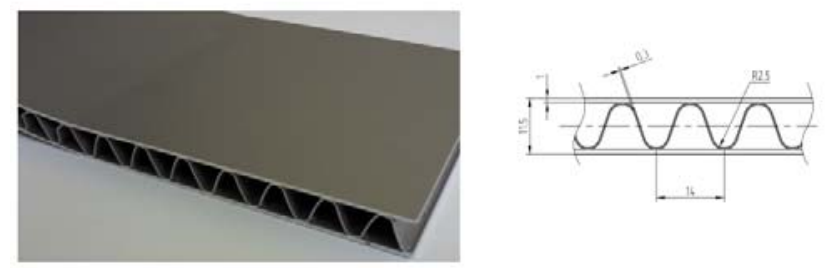

Rys. 2.5 Aluminiowa belka trójwarstwowa $\mathrm{z}$ rdzeniem z blachy falistej

Ze względu na kierunek ułożenia fal blachy rdzenia rozróżniono belki z rdzeniem ułożonym wzdłuż oraz poprzecznie do dłuższego jej boku. Modele obliczeniowe obejmujące ćwiartkę belki pokazano na rys. 2.6.

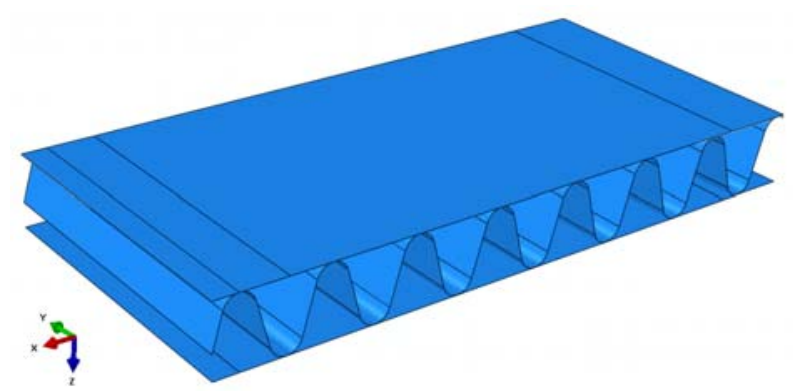

a) belka z rdzeniem pofałdowanym wzdłużnie

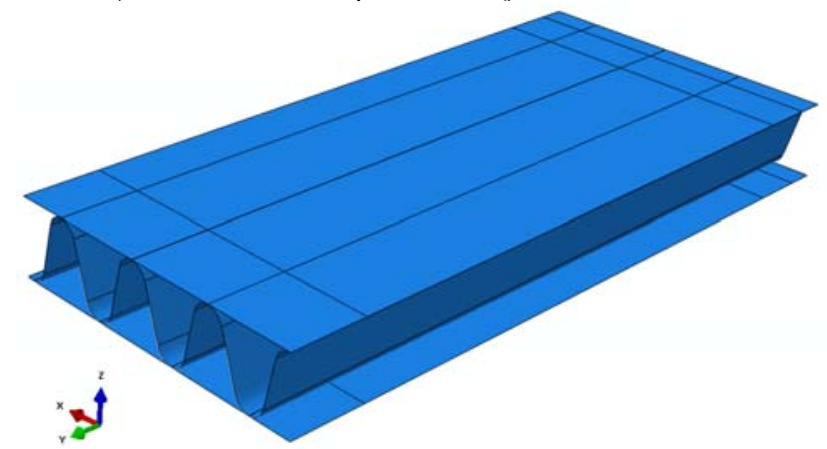

b) belka z rdzeniem pofałdowanym poprzecznie

Rys. 2.6. Modele obliczeniowe belek z rdzeniem z blachy falistej
Dla belki z rdzeniem pofałdowanym wzdłużnie przyłożono obciążenie tak, aby wywołać w niej zginanie czteropunktowe momentem gnącym o wartości $150 \mathrm{Nm}$, natomiast dla belki z rdzeniem pofałdowanym poprzecznie o wartości $200 \mathrm{Nm}$.

Maksymalne wartości przemieszczeń pionowych oraz ugięcia względne na bazie pomiarowej dla poszczególnych typów belek zestawiono w Tabeli 1 .

\section{Badania stanowiskowe struktur trójwarstwo- wych}

W ramach prac zrealizowanych $\mathrm{w}$ projekcie przeprowadzono, na specjalnie skonstruowanym stanowisku badawczym, badania eksperymentalne zginania próbek belek trójwarstwowych z rdzeniem o różnej budowie.. W pracy [4] omówiono szczegóły realizacji badań oraz zestawiono wyniki pomiarów. Widok ogólny stanowiska do badań czteropunktowego zginania zaprezentowano na rys.3.1. W trakcie badań rejestrowano wartości obciążeń oraz ugięć próbek.
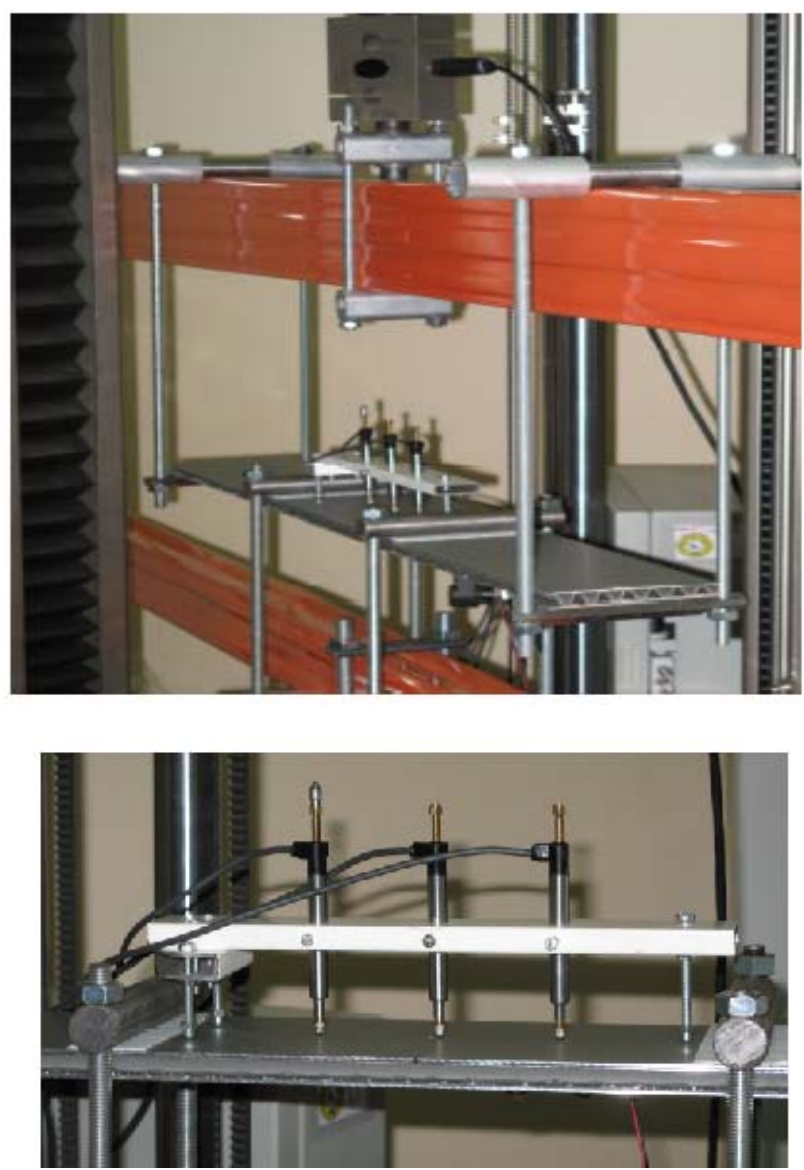

Rys. 3.1. Widok ogólny stanowiska do badań próbek belek trójwarstwowych oraz układu pomiarowego [4]

\section{Porównanie wyników obliczeń i badań ekspe- rymentalnych}

$\mathrm{Na}$ rys. $4.1 \div 4.4$ przedstawiono porównanie rezultatów obliczeń numerycznych i badań eksperymentalnych w postaci wykresów zależności ugięcia 
Zestawienie przemieszczeń pionowych dla poszczególnych typów belek

Tabela 1

\begin{tabular}{|c|c|c|c|c|c|c|}
\hline L.p. & \multicolumn{2}{|c|}{ Typ struktury rdzenia belki } & $\mathrm{U}_{1}[\mathrm{~mm}]$ & $\mathrm{U}_{2}[\mathrm{~mm}]$ & $\mathrm{U}_{3}[\mathrm{~mm}]$ & $? \mathrm{U}[\mathrm{mm}]$ \\
\hline 1 & \multirow{2}{*}{$\begin{array}{l}\text { Blacha } \\
\text { falista }\end{array}$} & Pofałdowanie wzdłużne & 26,16 & 26,72 & 26,16 & 0,56 \\
\hline 2 & & $\begin{array}{c}\text { Pofałdowanie poprzecz- } \\
\text { ne }\end{array}$ & 23,28 & 23,74 & 23,28 & 0,46 \\
\hline 3 & & Piana metalowa & 7,61 & 7,69 & 7,61 & 0,08 \\
\hline 4 & & lowa „plastra miodu” & 10,9 & 11,02 & 10,9 & 0,12 \\
\hline
\end{tabular}

belek od momentu gnącego. Pomiary wartości ugięć dokonano w części środkowej na bazie pomiarowej $\left(\mathrm{U}_{1}, \mathrm{U}_{2}, \mathrm{U}_{3}\right.$ według rys. 2.1).

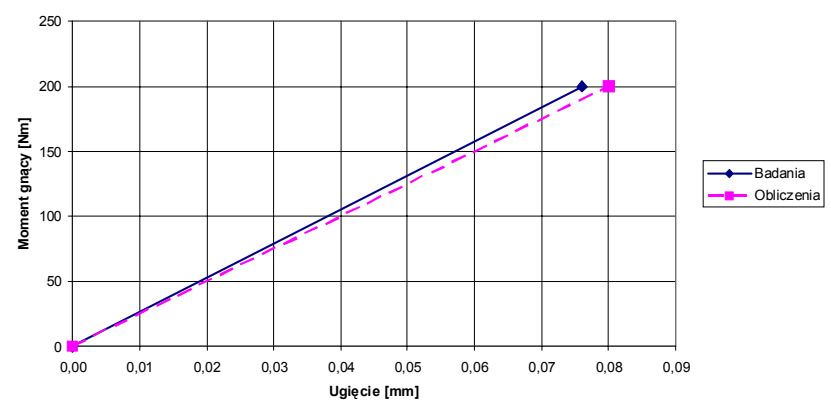

Rys. 4.1. Porównanie wyników obliczeń numerycznych i badań eksperymentalnych dla zginania 4-punktowego belki trójwarstwowej z rdzeniem z piany metalowej

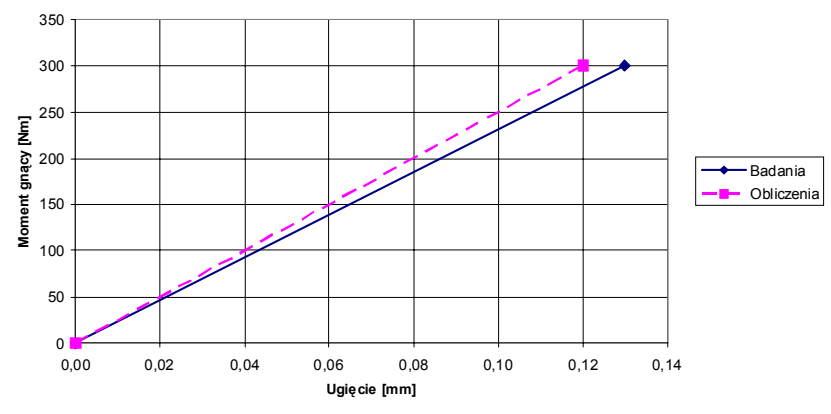

Rys. 4.2. Porównanie wyników obliczeń numerycznych i badań eksperymentalnych dla zginania 4-punktowego belki trójwarstwowej z rdzeniem o budowie ulowej (,plastra miodu”)

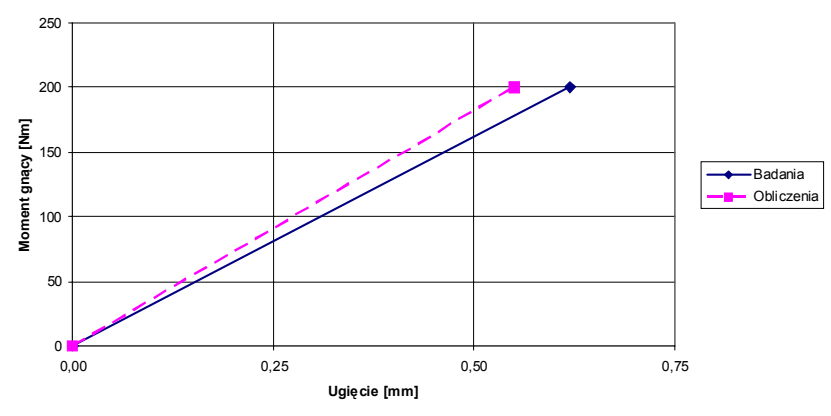

Rys. 4.3. Porównanie wyników obliczeń numerycznych i badań eksperymentalnych dla zginania 4-punktowego belki trójwarstwowej z poprzecznym pofałdowaniem rdzenia

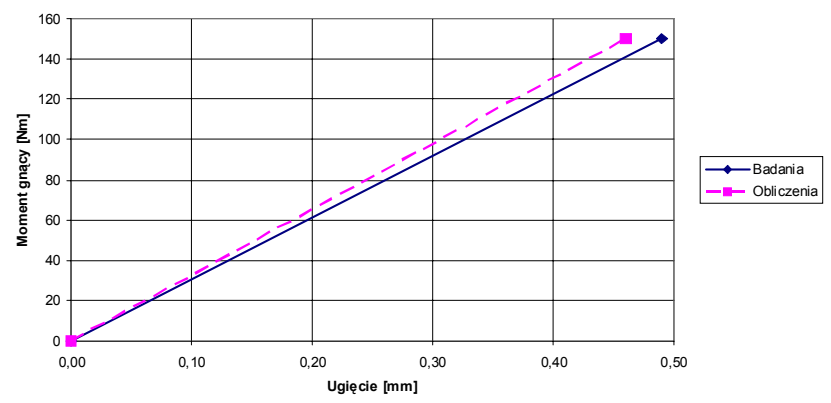

Rys. 4.4. Porównanie wyników obliczeń numerycznych i badań eksperymentalnych dla zginania 4-punktowego belki trójwarstwowej z wzdłużnym pofałdowaniem rdzenia

\section{Podsumowanie}

$\mathrm{Z}$ rezultatów analiz przedstawionych $\mathrm{w}$ tabeli 1 można zauważyć pewne prawidłowości. Sztywność na zginanie belek trójwarstwowych z rdzeniem wykonanym z piany metalowej lub ,plastra miodu” są zbliżone do siebie. Świadczy to o tym, że dla przyjętego ksztaltu i geometrii przekroju poprzecznego belki, wpływ struktury zastosowanego rdzenia na sztywność jest niewielki.

W przypadku belek trójwarstwowych z rdzeniem z blachy falistej, sztywność na zginanie jest tylko w niewielkim stopniu uzależniona od kierunku pofałdowania blachy rdzenia.

Różnice w ugięciach pomiędzy wymienionymi grupami belek wynikają z odmiennej geometrii przekroju poprzecznego.

$\mathrm{Z}$ przedstawionego $\mathrm{w}$ punkcie 4 porównania rezultatów analiz numerycznych i badań eksperymentalnych ugięć belek o budowie trójwarstwowej $\mathrm{z}$ rdzeniem o różnych strukturach wynika, że rozbieżności między nimi nie przekraczają 10\%. Można, więc stwierdzić, że opracowane modele obliczeniowe odwzorowują w sposób zadawalający własności mechaniczne analizowanych struktur konstrukcyjnych.

\section{Lit eratura}

[1] Allen H.G., Analysis and design of structural sandwich panels. Oxford, London, Edinburgh, New York, Toronto, Sydney, Paris, Braunschweig, Pergamon Press 1969.

[2] Plantema F.J., Sandwich construction. New York, London, Sydney, John Wiley\&Sons 1966.

[3] Studium budowy ustrojów nośnych nadwozi wagonów i konstrukcji nośnych wózków pod kątem optymalizacji stosunku nośności do ich masy (dla nadwozi wagonów pasażerskich typu $Z$, wagonów towarowych, wagonów czołowych zespołów trakcyjnych, tramwajów oraz wózków jedno i dwuosiowych), Instytut Pojazdów Szynowych „,TABOR”-Poznań, Poznań, 2010, OR-9772 (niepublikowane)

[4] Wasilewicz P., Jasion P., Badania wytrzymałościowe struktur typu sandwich. Politechnika Poznańska (21-361/2010), Poznań 2010 (niepublikowane) 